\title{
Variants in the vitamin D pathway, serum levels of vitamin $D$, and estrogen receptor negative breast cancer among African-American women: a case-control study
}

Song Yao ${ }^{1 *}$, Gary Zirpoli', Dana H Bovbjerg², Lina Jandorf ${ }^{3}$, Chi Chen Hong ${ }^{1}$, Hua Zhao ${ }^{1}$, Lara E Sucheston ${ }^{1}$, Li Tang ${ }^{1}$, Michelle Roberts' ${ }^{1}$ Gregory Ciupak', Warren Davis ${ }^{1}$, Helena Hwang ${ }^{4}$, Candace S Johnson ${ }^{5}$, Donald L Trump ${ }^{6}$, Susan E McCann ${ }^{1}$, Foluso Ademuyiwa ${ }^{6}$, Karen S Pawlish? ${ }^{7}$, Elisa V Bandera ${ }^{8}$ and Christine B Ambrosone

\begin{abstract}
Introduction: American women of African ancestry (AA) are more likely than European Americans (EA) to have estrogen receptor (ER)-negative breast cancer. 25-hydroxyvitamin D (25OHD) is low in AAs, and was associated with ER-negative tumors in EAs. We hypothesized that racial differences in $25 \mathrm{OHD}$ levels, as well as in inherited genetic variations, may contribute, in part, to the differences in tumor characteristics.

Methods: In a case $(n=928)$-control $(n=843)$ study of breast cancer in AA and EA women, we measured serum 25OHD levels in controls and tested associations between risk and tag single nucleotide polymorphisms (SNPs) in VDR, CYP24A1 and CYP27B1, particularly by ER status.

Results: More AAs had severe vitamin D deficiency (< $10 \mathrm{ng} / \mathrm{ml}$ ) than EAs (34.3\% vs 5.9\%), with lowest levels among those with the highest African ancestry. Associations for SNPs differed by race. Among AAs, VDR SNP rs2239186, associated with higher serum levels of $25 \mathrm{OHD}$, decreased risk after correction for multiple testing $(\mathrm{OR}=0.53,95 \% \mathrm{Cl}=$ $0.31-0.79, p$ by permutation $=0.03$ ), but had no effect in EAs. The majority of associations were for ER-negative breast cancer, with seven differential associations between AA and EA women for CYP24A1 ( $p$ for interaction $<0.10$ ). SNP rs27622941 was associated with a > twofold increased risk of ER-negative breast cancer among AAs $(O R=2.62,95 \% \mathrm{Cl}$ $=1.38-4.98)$, but had no effect in EAs. rs 2209314 decreased risk among EAs $(\mathrm{OR}=0.38,95 \% \mathrm{Cl}=0.20-0.73)$, with no associations in AAs. The increased risk of ER-negative breast cancer in AAs compared to EAs was reduced and became non-significant ( $\mathrm{OR}=1.20,95 \% \mathrm{Cl}=0.80-1.79)$ after adjusting for these two CYP24A1 SNPs.
\end{abstract}

Conclusions: These data suggest that genetic variants in the vitamin D pathway may be related to the higher prevalence of ER-negative breast cancer in AA women.

\section{Introduction}

American women of African ancestry (AA) are more likely to develop breast cancer at a younger age than those with European ancestry (EA) and are more likely to have tumors with aggressive characteristics, including high histological grade, negative estrogen receptor (ER)

\footnotetext{
* Correspondence: song.yao@roswellpark.org

'Department of Cancer Prevention \& Control, Roswell Park Cancer Institute,

Elm and Carlton Streets, Buffalo, NY 14263, USA

Full list of author information is available at the end of the article
}

status, and basal-like - ER ${ }^{-}$and/or progesterone receptor (PR) ${ }^{-}$, HER2 ${ }^{-}$, and cytokeratin $5 / 6^{+}$and/or HER $1^{+}$-features $[1,2]$. The reasons for these racial disparities are unknown.

It is clear that, among geographically diverse populations, certain genotypic and phenotypic characteristics may be selected for in response to local environmental pressures [3]. Skin pigmentation, the primary factor that provides protection from ultraviolet (UV) radiation, is correlated with latitude, and dark skin pigmentation is 
likely to be the original ancestral trait in humans. Migrations to Europe and Asia eventually gave rise to decreased pigmentation and lighter skin [4-6]. As much as $90 \%$ of vitamin D is derived from sun exposure, but high skin melanin concentration prevents penetration of UVB light and compromises synthesis efficiency by 10 to 50 times [7]. Although high pigmentation would reduce absorption of vitamin $\mathrm{D}$, intense sun exposure in subSaharan Africa would compensate. However, in high-latitude areas where UVB intensity is low and where more time may be spent indoors (particularly in winter), vitamin D deficiency may result among individuals with higher skin pigmentation. Indeed, in the US, the prevalence of 25-hydroxyvitamin D (25OHD) of less than 15 $\mathrm{ng} / \mathrm{mL}$ is almost 10 times higher in AA than in EA women [8], and the prevalence of severe vitamin D deficiency (<10 ng/mL) among AAs was 29\% in 2001 to 2004 [9]. In contrast, in Guinea-Bissau, the average $25 \mathrm{OHD}$ levels in healthy Africans were $34 \mathrm{ng} / \mathrm{mL}$, and the prevalence of severe vitamin D deficiency was as low as $1 \%[10]$.

Endogenous 25OHD may also be affected by variability in metabolic pathways, and synthesis and metabolism catalyzed by two major enzymes, $1 \alpha$-hydroxylase and 24-hydroxylase, which are encoded by $C Y P 27 B 1$ and CYP24A1, respectively. Binding of vitamin D to the vitamin D receptor (VDR) activates or suppresses gene transcription, depending on the type of response elements [11], and genetic variability in the above genes, known to differ by ancestry [12], is likely to affect vitamin D signaling.

Laboratory, preclinical, and clinical findings support the hypothesis that low levels of vitamin D are related to breast cancer risk. In the human mammary gland, VDR is expressed in all cell types [13], and vitamin D treatment inhibits breast cancer cell proliferation, induces cell apoptosis, and prevents carcinogenesis in rodent models $[14,15]$. However, epidemiologic evidence for associations between vitamin $\mathrm{D}$ and breast cancer risk is considered 'limited' [16], and one randomized trial showed little impact of vitamin D supplementation on breast cancer incidence [17]. These inconclusive findings could be due to tumor heterogeneity, which implies that the effects of vitamin D may only present in specific breast cancer subtypes. In fact, $V d r$ knockout mice were more likely than their wild-type littermates to develop $\mathrm{Er} / \mathrm{Pr}^{-}$tumors [18]. Consistent with results from these preclinical studies, some epidemiologic studies have also indicated that effects of vitamin D may be strongest for breast cancers with poor prognostic characteristics and that lower serum 25OHD levels are found among women with ER ${ }^{-}$compared with $\mathrm{ER}^{+}$tumors [19-21]. Recently, we reported lower levels of serum 25OHD in women with high- versus low-grade breast tumors and in women with triple-negative versus luminal A breast tumors [22]

Here, we examined levels of $25 \mathrm{OHD}$ in AA and EA women without breast cancer in relation to self-reported race as well as ancestry, which was estimated by using ancestry informative markers (AIMs). 25OHD levels in women with breast cancer could be a result of disease processes, and some samples were obtained after chemotherapy was initiated; thus, we did not compare serum levels of $25 \mathrm{OHD}$ between cases and controls. Instead, we evaluated variants in vitamin $\mathrm{D}$ activity and major metabolism (VDR, CYP27B1, and CYP24A1) in relation to breast cancer risk, particularly in relation to self-reported race and estrogen receptor status. We also tested whether vitamin D-related genetic variants could explain, in part, the higher prevalence of ER ${ }^{-}$breast cancer among AA women.

\section{Materials and methods Study population}

The Women's Circle of Health Study (WCHS) is an ongoing study designed specifically to examine the role of genetic and non-genetic factors in early/aggressive breast cancer in AA and EA women. Study design, enrollment, and collection of data and biospecimens have been described in detail previously [23]. Briefly, women with diagnosed incident breast cancer were identified through both hospital-based case ascertainment in targeted hospitals that had large referral patterns of AAs in four boroughs of the metropolitan New York City area and population-based case ascertainment in seven counties in New Jersey through the New Jersey State Cancer Registry. The eligibility criteria for cases were the following: self-identified AA and EA women, 20 to 75 years of age at diagnosis, no previous history of cancer other than non-melanoma skin cancer, recent diagnosis of primary, histologically confirmed breast cancer, and Englishspeaking. EA women with breast cancer, more prevalent in the catchment area than AA cases, were randomly selected for recruitment and were matched by age and county to AA cases. Controls who did not have a history of diagnosis of any cancer other than non-melanoma skin cancer and who were living in the same area as cases were identified through random digit dialing and were matched to cases by self-reported race and 5-year age categories. After agreement to participate was obtained, in-person interviews were conducted to complete informed consent and to query participants on a number of potential risk factors, including medical history, family history of cancer, diet, physical activity, and other lifestyle factors. Anthropometric measures were taken, and biospecimens were collected. Blood samples were initially collected, but owing to logistical and cost constraints, we transitioned to saliva samples after the enrollment of 
approximately 850 participants. Permission to obtain pathology data, including ER status, and tumor tissue blocks was included in the informed consent form. The participation rates were $80.2 \%$ and $53.4 \%$ for AA cases and controls, respectively, and $80.0 \%$ and $48.9 \%$ for EA cases and controls, respectively. This study was approved by the institutional review boards of the Roswell Park Cancer Institute, the Cancer Institute of New Jersey, the Mount Sinai School of Medicine, and the participating hospitals in New York City. At the time of the genotyping (April 2010), DNA and data were available for 553 AA cases and 466 AA controls and 383 EA cases and 382 EA controls from the WCHS.

\section{Selection of multi-population tag single-nucleotide polymorphisms}

We used a two-step approach to select a set of multipopulation tag single-nucleotide polymorphisms (SNPs) that represent common genetic variations - minor allele frequency of at least 0.05 - in $V D R$ in both AA and EA populations. First, 122 SNPs in the VDR region plus $15-\mathrm{kb}$ regions from both 3' and 5' ends were selected from HapMap [24] and other resequencing projects by using the Genome Variation Server at SeattleSNPs [25]. These SNPs were then genotyped in $60 \mathrm{AA}$ and 60 EA controls. With the TAGster program [26], 49 multi-population tag SNPs were subsequently selected for genotyping in the WCHS. Also among those VDR variants finally selected were commonly studied SNPs, including Cdx2 (rs11568820), Fok1 (rs2228570), Bsm1 (rs1544410), Apa1 (rs7975232), and Taq1 (rs731236). For CYP24A1, 15 multi-population tag SNPs were selected by using publicly available CEU (Utah residents with ancestry from Northern and Western Europe) and YRI (Yoruba in Ibadan) genotype data from HapMap. For $C Y P 27 B 1$, only one SNP had a minor allele frequency of at least 0.05 in the dbSNP database and was thus included. To control for potential bias due to population admixture and to examine serum 25OHD levels in relation to ancestry, a panel of 108 AIMs that have been shown to be effective in correcting for admixture in casecontrol studies [27] was chosen.

\section{Genotyping}

DNA was extracted from blood samples by using FlexiGene $^{\mathrm{TM}}$ DNA kits (Qiagen, Valencia, CA, USA) in accordance with the instructions of the manufacturer and from saliva collected in Oragene ${ }^{\mathrm{TM}}$ kits (DNA Genotek Inc., Kanata, ON, Canada). Genomic DNA was evaluated and quantified by a Nanodrop UV spectrometer (Thermo Fisher Scientific Inc., Wilmington, DE, USA) and a PicoGreen-based fluorometric assay (Molecular Probes, now part of Invitrogen Corporation, Carlsbad, CA, USA) and stored at $-80^{\circ} \mathrm{C}$ until analysis. Selected tag SNPs and AIMs were genotyped by an Illumina GoldenGate assay (Illumina
Inc., San Diego, CA, USA) at the Genomics Core Facility at the Roswell Park Cancer Institute. Five percent duplicates and two sets of in-house trio samples were included for quality control purposes. The average successful genotyping rate for each sample and each SNP was at least 99\%, and no SNPs violated Hardy-Weinberg equilibrium in controls or mendelian inheritance. Clustering plots of SNPs that were significant in the statistical analysis were manually re-inspected post hoc to ensure that the calls were robust.

Measurement of serum levels of $250 \mathrm{HD}$ in WCHS controls Serum samples were available from 242 AA and 187 EA women in the control group and were used to measure levels of 25OHD by immunochemiluminometric assay. The assay coefficient of variation was $10.3 \%$.

\section{Statistical analysis \\ Estimation of ancestry and comparison of serum levels of 25OHD}

Individual ancestral proportions for EA and AA were estimated with the Bayesian Markov chain Monte Carlo clustering algorithm implemented in STRUCTURE 2.3 [28]. We included publicly available genotypes from the YRI and CEU ancestral populations, and the program was run multiple times assuming $\mathrm{K}=2$ underlying ancestries. Women with more than $85 \%$ of genomic race other than the self-identified race were excluded from the analysis ( $n$ =13); therefore, 547 AA cases and 461 AA controls and 381 EA cases and 382 EA controls were included in the final analyses for SNPs and breast cancer risk. There were no exclusions due to conflicting self-report and marker ancestry in the serum analyses performed in controls only. To compare serum levels of $25 \mathrm{OHD}$ between AA and EA women, least squares means and standard errors were calculated with adjustment for age, body mass index (BMI), and season of blood collection (four seasons). To test genotype-phenotype correlations between SNPs and 25OHD levels in controls, the Pearson correlation test was used and genotypes were coded as 0,1 , and 2 to reflect the number of copies of the minor allele.

Associations between breast cancer risk and genotypes and haplotypes

Descriptive variables were analyzed by Student $t$ test or chi-squared test. All genotype analyses were performed for AA and EA populations separately. A genotypic (co-dominant) model was assumed for SNP effects. When genotype frequencies of the rare homozygote were not more than $5 \%$ in both populations, categories were collapsed (homozygote rare and heterozygote) for power considerations. To test whether there was a linear dose effect of the variant alleles (log-additive genetic model for trend test), SNPs were coded as 0,1 , and 2 as described above. Univariate single SNP analysis was performed, and resulting 
$P$ values were plotted after logarithm transformation with accompanying linkage disequilibrium (LD) map by using the snp.plotter R package [29]. Covariates, including age at diagnosis, BMI, European ancestry, family history of breast cancer, and education, were then adjusted in multivariate logistic regression models to derive odds ratios (ORs) and 95\% confidence intervals (CIs).

For $V D R$ and $C Y P 24 A 1$, haplotype structure was determined by using the method of Gabriel and colleagues [30], and each haplotype was tested in the regression model in comparison with all other haplotypes. For both single SNP and haplotype analyses, we controlled the family-wise error rate by using permutation testing $(n=10,000)$ as implemented in PLINK [31].

Potential modification of associations by race, menopausal status, and estrogen receptor status

To examine whether the associations of SNPs with breast cancer risk differed between AA and EA women, interaction with race was tested by including a race*SNP term in the logistic regression model without an estimate of ancestry. A similar approach was used to test modification effects by menopausal status.

To test whether selected SNPs contributed to differential risk of $\mathrm{ER}^{-}$breast cancer between AA and EA women, OR of $E R^{-}$breast cancer by race was first estimated from a base model containing race and other covariates. SNPs that were differentially associated with $\mathrm{ER}^{-}$breast cancer risk by race ( $P$ for interaction was less than 0.10 ) were then entered in the base model and subjected to backward selection. A substantial reduction of OR ( $\geq 10 \%$ ) for AA versus EA race by adding selected SNPs would indicate that those SNPs explained, in part, the higher risk of $E^{-}$ breast cancer in AA than in EA women.

\section{Results}

\section{Descriptive characteristics}

Table 1 summarizes the descriptive characteristics of the study population by self-reported race. The majority of the women were pre-menopausal at the time of cancer diagnosis (62\%) or enrollment for controls (57\%). Overall, AA women had higher BMIs than EA women (31.3 versus $27.2 \mathrm{~kg} / \mathrm{m}^{2}$ ) and were less likely to have a college education or beyond (57.5\% versus $82.0 \%$ ), to take hormone replacement therapy after menopause (14.0\% versus $24.1 \%)$, or to have a family history of breast cancer in firstdegree relatives (13.5\% versus $22.4 \%$ ) (all $P<0.001$ ). There were no significant case-control differences in AAs or EAs, except that in EA women, cases were less likely than controls to have a college education and more likely to have a positive family history of breast cancer $(P \leq 0.001)$.

\section{Serum levels of $250 H D$}

Among controls, serum levels of 25OHD were lower in AA than EA women (least squares means and standard errors after age, BMI, and season of blood collection were controlled for: $14.9 \pm 0.5$ versus $21.4 \pm 0.6 \mathrm{ng} / \mathrm{mL}$; $P<0.001)$. As shown in Figure 1a, the rate of vitamin $D$ severe deficiency $(<10 \mathrm{ng} / \mathrm{mL})$ was almost sixfold higher in AA than EA women (34.3\% versus 5.9\%). On the basis of publicly available gene expression data in cultured lymphoblastoid cell lines (LCLs) from the HapMap CEU and YRI populations [32], estimated average expression levels of VDR were significantly lower in LCLs from the African population than in those from the European population ( $\log _{2}$-transformed level mean \pm standard deviation: $6.54 \pm 0.47$ versus $6.96 \pm 0.53 ; \mathrm{q}$ value after controlling for multiple comparison: $1.30 \times$ $10^{-5}$ ) (Figure 1b). We categorized AA women by proportion of African ancestry (<85\%, $85 \%$ to $94 \%$, and $\geq 95 \%$ ) and found that women with the lowest African ancestry had the highest serum 25OHD levels $(15.5 \mathrm{ng} / \mathrm{mL})$ but that those with the greatest African ancestry ( $\geq 95 \%)$ had the lowest levels $(13.7 \mathrm{ng} / \mathrm{mL})(P=0.07)$. When correlations between SNPs and serum 25OHD levels in AA and EA women were tested, the minor allele of VDR SNP rs2239186 was significantly associated with increased levels of $25 \mathrm{OHD}$ in AAs. For the AA, AG, and GG genotypes, the means and standard deviations of serum $25 \mathrm{OHD}$ were $13.5 \pm 6.5,16.3 \pm 8.7$, and 21.2 $\pm 12.2 \mathrm{ng} / \mathrm{mL}$, respectively $(P=0.006)$. However, the differences were not significant in EA women (21.0, 23.8, and $22.1 \mathrm{ng} / \mathrm{mL}$ for the AA, AG, and GG genotypes, respectively; $P=0.20$ ).

\section{Associations between genetic variants and breast cancer risk by self-reported race}

In addition to circulating 25OHD levels, there were racial differences in genetic variants. Of the 65 SNPs genotyped, $51(79 \%)$ displayed significantly different allele frequencies by self-reported race $(P<0.05) ; 12$ of these SNPs were the rare variant in one group (AA or EA) but the common allele in the other group (Table S1 of Additional file 1). LD in VDR and CYP24A1 also displayed different patterns by race, as shown in Figures 2 and 3. Also shown in the figures are unadjusted $P$ values for associations between single SNPs and breast cancer risk (see Table S1 of Additional file 1 for results of all SNPs). In AA women, four SNPs in $V D R$ - rs12721364, rs2239186, rs886441, and rs11568820 (Cdx2) - but none in CYP24A1 were associated with breast cancer risk at a nominal significance level of 0.05 (Figures 2a and 3a). The association of $V D R$ rs2239186 remained significant after correction for multiple testing $(P=0.03)$. In EA women, two SNPs in $V D R$ rs11608702 and rs7975332 (Apa1) - and three SNPs in CYP24A1 - rs912505, rs3787555, and rs2244719 - were associated with breast cancer risk $(P<0.05)$ (Figures $2 \mathrm{~b}$ and $3 \mathrm{~b}$ ) but did not remain significant after multiple comparisons were controlled for (data not shown). There were 
Table 1 Descriptive characteristics of African-American and European-American women by case-control status in the Women's Circle of Health Study

\begin{tabular}{|c|c|c|c|c|c|c|}
\hline \multirow{3}{*}{ Characteristics } & \multicolumn{3}{|c|}{ African-American } & \multicolumn{3}{|c|}{ European-American } \\
\hline & $\begin{array}{c}\text { Case } \\
(n=547)\end{array}$ & $\begin{array}{l}\text { Control } \\
(n=461)\end{array}$ & $P$ value & $\begin{array}{c}\text { Case } \\
(n=381)\end{array}$ & $\begin{array}{c}\text { Control } \\
(n=382)\end{array}$ & $P$ value \\
\hline & Mean (SD) & Mean (SD) & & Mean (SD) & Mean (SD) & \\
\hline Age, years & $51.7(10.0)$ & $49.8(9.9)$ & 0.003 & $51.0(8.4)$ & $50.9(8.3)$ & 0.82 \\
\hline Body mass index, $\mathrm{kg} / \mathrm{m}^{2}$ & $31.2(6.7)$ & $31.6(7.8)$ & 0.48 & $26.8(5.8)$ & $27.7(7.1)$ & 0.06 \\
\hline \multirow[t]{2}{*}{ Percentage with European ancestry } & $0.09(0.15)$ & $0.10(0.16)$ & 0.19 & $0.98(0.07)$ & $0.99(0.03)$ & 0.07 \\
\hline & Count (\%) & Count (\%) & & Count (\%) & Count (\%) & \\
\hline Menopausal status & & & 0.14 & & & 0.17 \\
\hline Pre-menopausal & $337(61.6)$ & $263(57.0)$ & & $235(61.7)$ & $217(56.8)$ & \\
\hline Post-menopausal & $210(38.4)$ & $198(43.0)$ & & $146(38.3)$ & $165(43.2)$ & \\
\hline Family history & & & 0.13 & & & 0.001 \\
\hline Yes & $82(15.0)$ & $54(11.7)$ & & $104(27.3)$ & $67(17.5)$ & \\
\hline No & $465(85.0)$ & $407(88.3)$ & & $277(72.7)$ & $315(82.5)$ & \\
\hline Education & & & 0.06 & & & $<0.001$ \\
\hline Less than high school & $76(13.9)$ & 55 (11.9) & & $9(2.4)$ & $4(1.1)$ & \\
\hline High school & $175(32.0)$ & $122(26.5)$ & & $80(21.0)$ & $44(11.5)$ & \\
\hline College or above & $296(54.1)$ & $284(61.6)$ & & $292(76.6)$ & $334(87.4)$ & \\
\hline Hormone replacement therapy & & & 0.74 & & & 0.47 \\
\hline Yes & 79 (14.5) & $62(14.2)$ & & $96(25.3)$ & $88(23.0)$ & \\
\hline No & $464(85.5)$ & $397(85.8)$ & & $284(74.7)$ & $294(77.0)$ & \\
\hline
\end{tabular}

For continuous variables, $P$ values were based on the $t$ test; for categorical variables, $P$ values were based on the chi-squared test. Owing to occasional missing values, the counts of some variables did not add up to the total. SD, standard deviation.

no associations between the SNP in $C Y P 27 B 1$ and breast cancer risk in either EA or AA women.

Table 2 shows ORs and 95\% CIs for four SNPs (rs11608702, rs12721364, rs2239186, and rs11568820) in $V D R$ and two SNPs (rs912505 and rs3787555) in CYP24A1 which had differential associations between AA and EA women ( $P$ for interaction by race was not more than 0.10) after adjustment for age, proportion of European ancestry, BMI, family history of breast cancer, and education. In AA women, the combined GG and AG genotypes of rs2239186, which remained significant after correction for multiple testing and were also related to increased levels of $25 \mathrm{OHD}$, were associated with an almost $50 \%$ reduction of risk of breast cancer in comparison with homozygotes for A alleles $(\mathrm{OR}=0.53,95 \% \mathrm{CI}=0.35$ to $0.79, P$ trend for the $\mathrm{G}$ allele $=0.001)$. Among AA women, a reduced risk associated with $V D R$ rs12721364 $(\mathrm{OR}=$ $0.53,95 \% \mathrm{CI}=0.31$ to $0.79, P=0.01$ ) and a marginally increased risk with SNP rs11568820 (Cdx2) (OR for AA genotypes $=1.94,95 \% \mathrm{CI}=1.01$ to $3.74, P=0.04)$ were observed.

Among EA women, the VDR 'at-risk' $\mathrm{G}$ allele for rs2239186 was more common in EA women but was not associated with breast cancer risk $(\mathrm{OR}=0.85,95 \% \mathrm{CI}=$ 0.62 to 1.17$)$, nor were $V D R$ rs 12721364 SNPs. There were increases in risk by the VDR SNP rs11608702 and significant decreases in risk by two $C Y P 24 A 1$ variants: rs912505 and rs3787555; however, these did not remain significant after correction for multiple testing.

Results from haplotype analysis were consistent with those from single SNP analysis for VDR rs2239186. Among AA women, a G-G-G haplotype consisting of this SNP and two neighboring variants was associated with a decreased risk of breast cancer after adjustment for multiple testing $(\mathrm{OR}=0.55,95 \% \mathrm{CI}=0.38$ to $0.81, P=0.04$ ) (Table S2 of Additional file 1). Among EA women, similar results were found for haplotypes containing rs11608702 in $V D R$ and haplotypes containing rs3787555 in CYP24A1. The commonly studied haplotype in the 3' untranslated region of $V D R$ consisting of Taq1, Apa1, and Bsm1 was not associated with breast cancer risk in AA women, but a modest decreased risk was observed in EA women and significance was marginal $(\mathrm{OR}=0.82,95 \% \mathrm{CI}=0.67$ to 1.02).

\section{Estrogen receptor-negative breast cancer and CYP24A1 variants}

Stratification by ER status revealed associations that were not observed in the overall analysis, and the majority of findings were observed only for $\mathrm{ER}^{-}$breast cancer (Tables S3 and S4 of Additional file 1). Although VDR rs10783218 was marginally associated with a twofold increased risk of $\mathrm{ER}^{+}$breast cancer among EA women and $V D R$ rs3819545 was associated with a decreased 
A. Vitamin D severe deficiency $(25 \mathrm{OHD}<10 \mathrm{ng} / \mathrm{ml})$

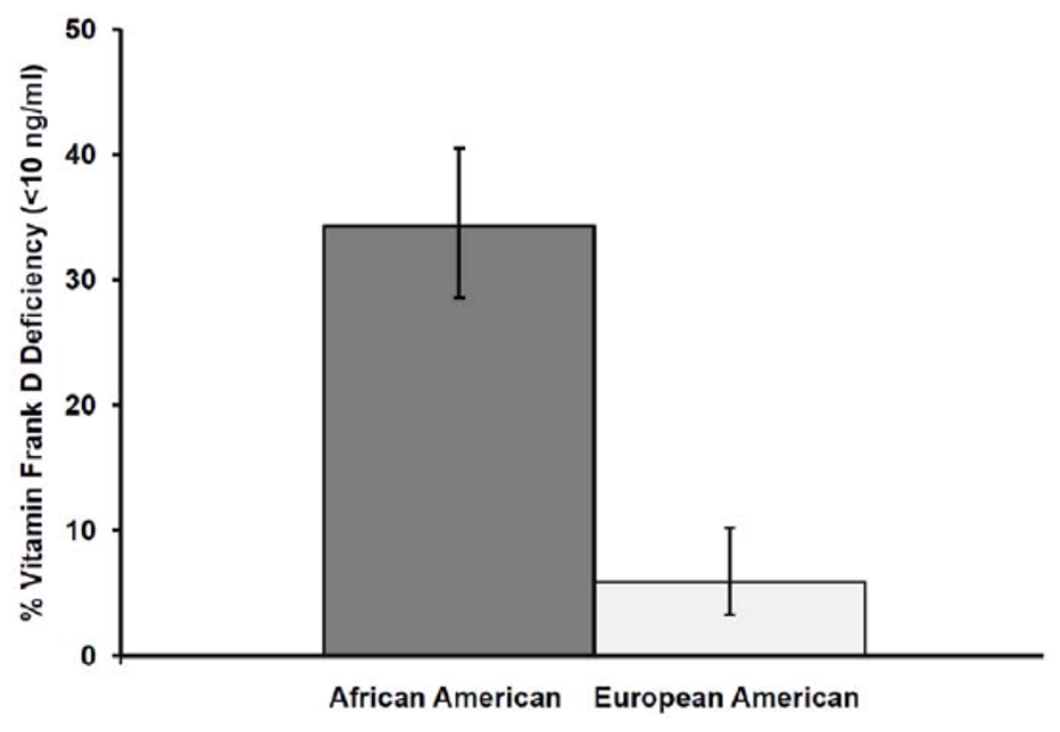

$250 \mathrm{HD}$ levels,

means \pm standard $\quad 14.9 \pm 0.5 \quad 21.4 \pm 0.6 \quad p<0.001$

error $(\mathrm{ng} / \mathrm{ml})$ :

B. Vitamin D receptor (VDR) expression in HapMap lymphoblastoid cell lines

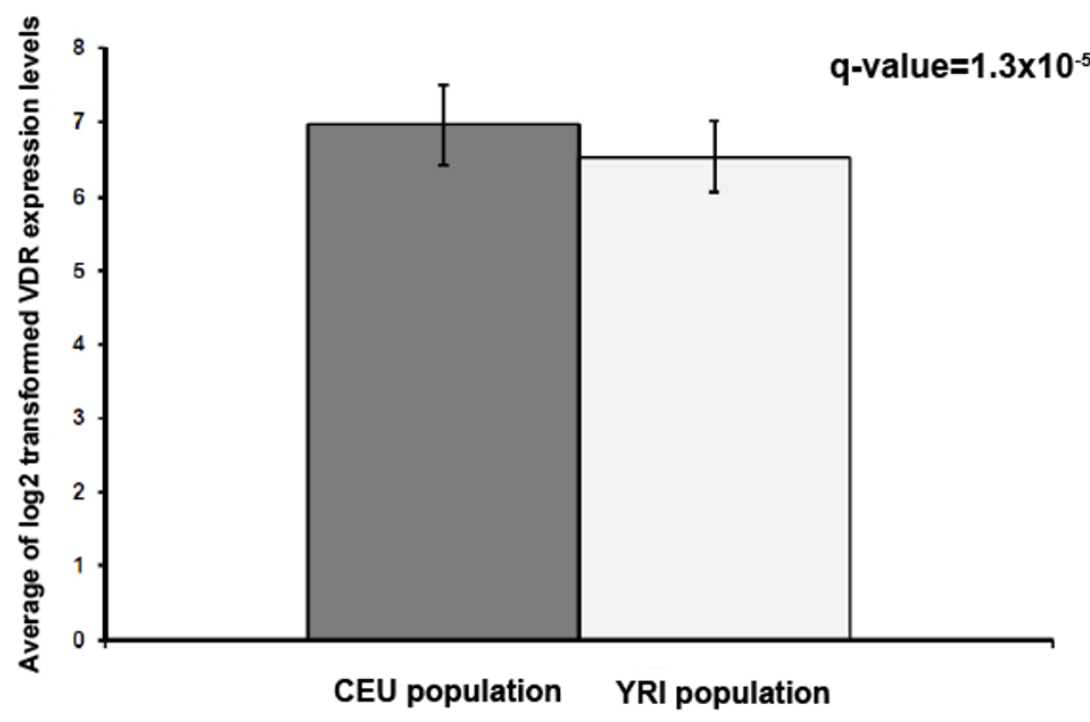

Figure 1 Serum 250HD and vitamin D receptor expression in populations of African and European ancestry. (a) The bars indicate the proportion of frank vitamin D deficiency - 25-hydroxyvitamin D (25OHD) of less than $10 \mathrm{ng} / \mathrm{mL}$ - and the $95 \%$ confidence interval. (b) The bars indicate the average of the $\log _{2}$-transformed gene expression levels of vitamin D receptor (VDR) in the HapMap lymphoblastoid cell lines from the CEU (Utah residents with ancestry from Northern and Western Europe) population and the YRI (Yoruba in Ibadan) population. The data were obtained from Zhang and colleagues [32]. 


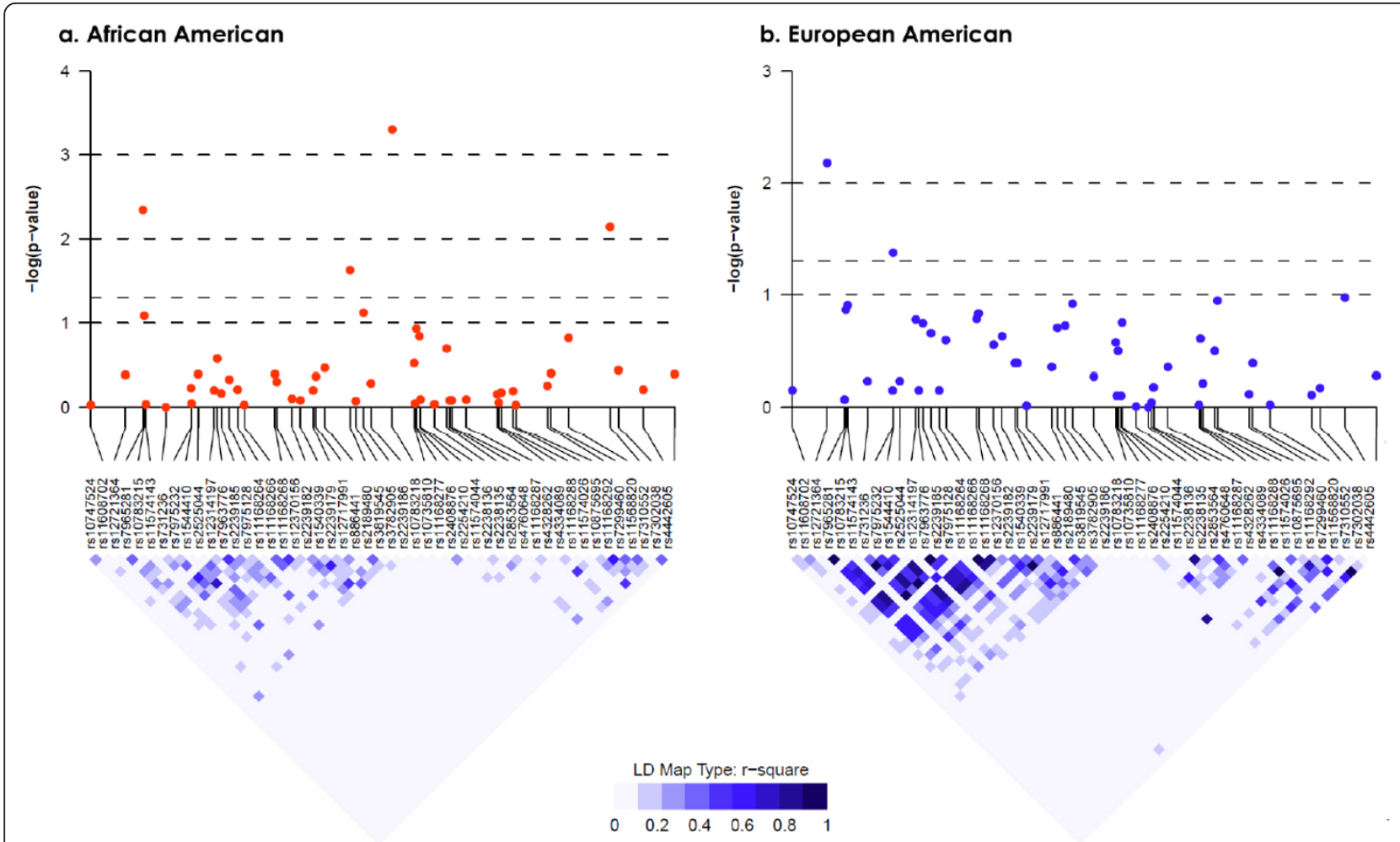

Figure 2 Logarithm-transformed $P$ values derived from univariate single-nucleotide polymorphism analysis of vitamin $D$ receptor (VDR). $P$ values were plotted with accompanying linkage disequilibrium (LD) map for African-American (a) and European-American (b) separately.

risk of $\mathrm{ER}^{-}$breast cancer, several SNPs in CYP24A1 were highly significantly associated with risk of ER ${ }^{-}$breast cancer. Importantly, results differed markedly between AA and EA women ( $P$ for interaction was not more than 0.10) (Table 3). For example, CYP24A1 rs27622941 was associated with a more than twofold increased risk of $\mathrm{ER}^{-}$breast cancer among AA women $(\mathrm{OR}=2.62$, $95 \% \mathrm{CI}=1.38$ to 4.98$)$ and there were no associations in EAs $(\mathrm{OR}=0.78,95 \% \mathrm{CI}=0.34$ to 1.78$)$. Conversely, CYP24A1 rs2209314 was associated with an almost threefold decreased risk of $\mathrm{ER}^{-}$breast cancer in EA women $(\mathrm{OR}=0.38,95 \% \mathrm{CI}=0.20$ to 0.73$)$ and there were no associations in AA women $(\mathrm{OR}=1.34,95 \% \mathrm{CI}=$ 0.74 to 2.40$)$.

To determine whether these SNPs contributed to the observed higher risk of $\mathrm{ER}^{-}$breast cancer in AA women in comparison with EA women, a base model containing self-reported race and other covariates was developed (Table 4). The base model showed an increased ER' cancer risk associated with $\mathrm{AA}$ race $(\mathrm{OR}=1.53,95 \% \mathrm{CI}=1.06$ to 2.22). The eight SNPs that showed significant interactions with race were tested in the base model. After backward selection, the two CYP24A1 SNPs shown above, rs2209314 and rs2762941, remained significant in the final model, reducing the risk associated with AA race by $22 \%$ and rendering it non-significant $(\mathrm{OR}=1.20,95 \% \mathrm{CI}=$ 0.80 to 1.79 ).

Lastly, there were significant interactions for two SNPs in $V D R$ with menopausal status (Table S5 of Additional file 1). The increased risk associated with rs 886441 in AA women was restricted to pre-menopausal women (OR = $2.27,95 \% \mathrm{CI}=1.32$ to 3.90 ), and the increased risk associated with rs7975232 (Apa1) in EA women was restricted to post-menopausal women $(\mathrm{OR}=2.24,95 \% \mathrm{CI}=1.19$ to 4.21).

\section{Discussion}

In this study, we found that relationships between breast cancer risk and variants in genes associated with vitamin D activity and metabolism, VDR and CYP24A1, differed depending upon self-reported race and that associations were most notable for risk of ER ${ }^{-}$breast cancer in both $A A$ and EA women. Importantly, we found that rs2209314 and rs2762941 in CYP24A1 contributed significantly to the higher risk of $\mathrm{ER}^{-}$breast cancer in AA than EA women. Among controls in the WCHS, serum levels of $25 \mathrm{OHD}$ were notably lower in AA women than EA women, the lowest levels were among women with the greatest African ancestry estimated by AIMs, and VDR expression levels, as estimated from published data 


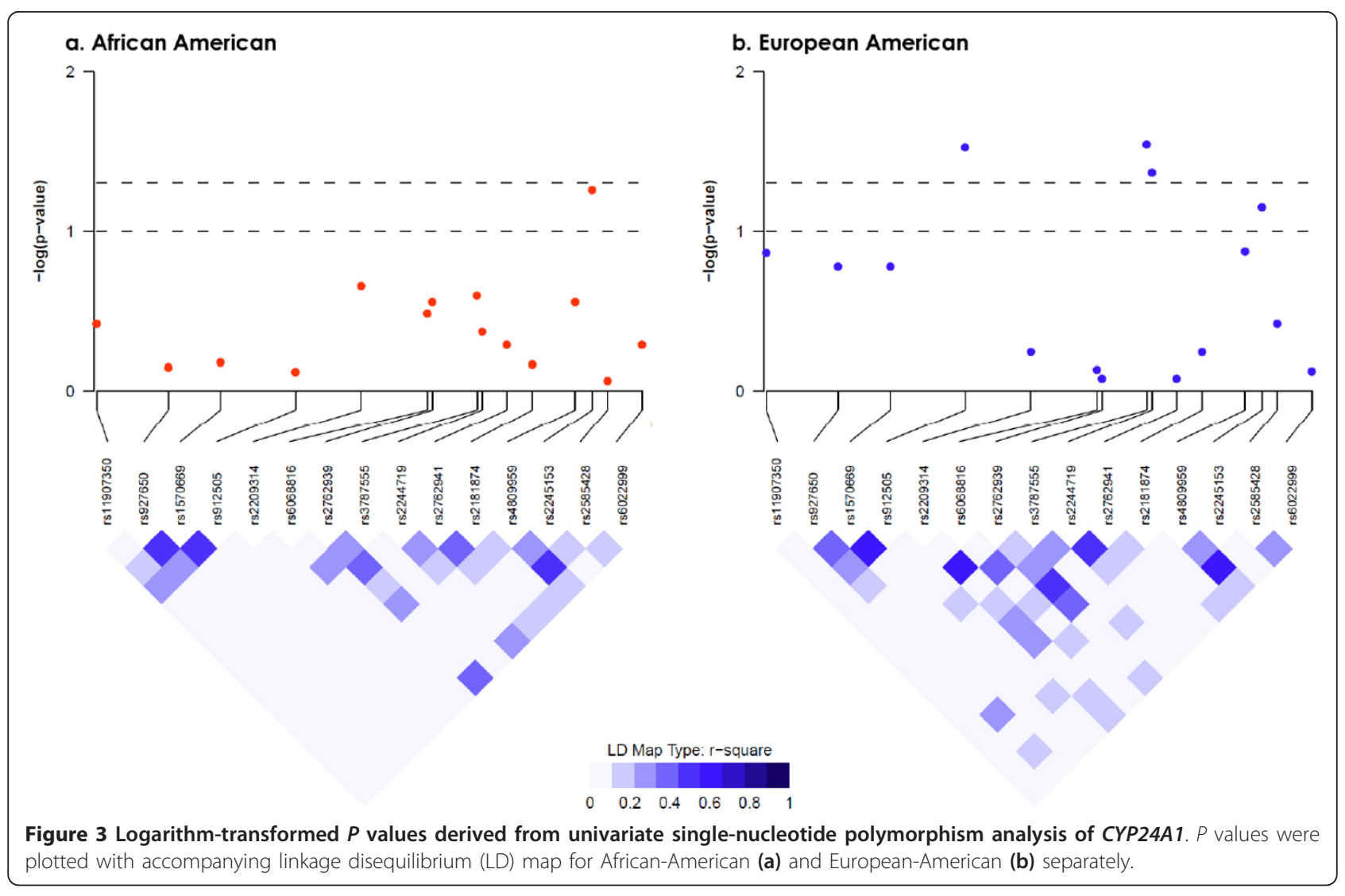

Table 2 Single-nucleotide polymorphisms in VDR and CYP24A1 and differential associations with breast cancer risk between African-American and European-American women in the Women's Circle of Health Study

\begin{tabular}{|c|c|c|c|c|c|c|c|c|c|}
\hline \multirow[b]{2}{*}{ Gene } & \multirow[b]{2}{*}{ SNP } & \multirow[b]{2}{*}{ Genotype } & \multicolumn{2}{|c|}{ African-American } & \multicolumn{4}{|c|}{ European-American } & \multirow[b]{2}{*}{$P_{\text {interaction }}$} \\
\hline & & & Cases/Controls & $\begin{array}{l}\text { Adjusted OR } \\
(95 \% \mathrm{Cl})\end{array}$ & $P_{\text {trend }}$ & Cases/Controls & $\begin{array}{l}\text { Adjusted OR } \\
(95 \% \mathrm{Cl})\end{array}$ & $P_{\text {trend }}$ & \\
\hline \multirow[t]{3}{*}{$V D R$} & rs11608702 & AA & $330 / 261$ & 1.00 & 0.37 & $166 / 190$ & 1.00 & 0.02 & 0.01 \\
\hline & & AT & $175 / 175$ & $0.80(0.61-1.04)$ & & 160/159 & $1.15(0.84-1.58)$ & & \\
\hline & & $\pi$ & $37 / 25$ & $1.13(0.65-1.95)$ & & $55 / 31$ & $1.88(1.14-3.09)$ & & \\
\hline \multirow[t]{2}{*}{$V D R$} & rs12721364 & $\mathrm{GG}$ & $520 / 420$ & 1.00 & 0.01 & $303 / 298$ & 1.00 & 0.90 & 0.02 \\
\hline & & GA/AA & $24 / 40$ & $0.53(0.31-0.90)$ & & 78/82 & $0.98(0.68-1.41)$ & & \\
\hline \multirow[t]{2}{*}{$V D R$} & rs2239186 & AA & 497/393 & 1.00 & $0.001^{\mathrm{a}}$ & $265 / 256$ & 1.00 & 0.46 & 0.01 \\
\hline & & $A G / G G$ & $47 / 68$ & $0.53(0.35-0.79)$ & & $115 / 125$ & $0.85(0.62-1.17)$ & & \\
\hline \multirow[t]{3}{*}{$V D R$} & rs11568820 (Cdx2) & GG & $18 / 26$ & 1.00 & 0.04 & $234 / 232$ & 1.00 & 0.68 & 0.04 \\
\hline & & GA & $143 / 140$ & $1.55(0.79-3.03)$ & & $129 / 132$ & $0.99(0.72-1.36)$ & & \\
\hline & & $\mathrm{AA}$ & $384 / 295$ & $1.94(1.01-3.74)$ & & 18/18 & $0.83(0.39-1.75)$ & & \\
\hline \multirow[t]{3}{*}{ CYP24A1 } & rs912505 & $\mathrm{AA}$ & $173 / 139$ & 1.00 & 0.71 & $236 / 216$ & 1.00 & 0.02 & 0.05 \\
\hline & & $A G$ & $268 / 244$ & $0.89(0.66-1.19)$ & & $132 / 139$ & $0.80(0.59-1.10)$ & & \\
\hline & & GG & 104/77 & $1.14(0.78-1.66)$ & & 13/27 & $0.36(0.17-0.76)$ & & \\
\hline \multirow[t]{3}{*}{ CYP24A1 } & rs3787555 & $\mathrm{CC}$ & $379 / 331$ & 1.00 & 0.14 & 206/183 & 1.00 & 0.03 & 0.02 \\
\hline & & CA & $154 / 123$ & $1.17(0.88-1.56)$ & & $149 / 155$ & $0.81(0.59-1.10)$ & & \\
\hline & & AA & $14 / 7$ & $1.88(0.73-4.83)$ & & 25/41 & $0.50(0.28-0.89)$ & & \\
\hline
\end{tabular}

Odds ratio (OR) and 95\% confidence interval $(\mathrm{Cl})$ are adjusted for covariates, including age, proportion of European ancestry, body mass index, family history of breast cancer, and education. $P_{\text {trend }}$ was for genetic dose response by coding genotypes as 0,1 , and 2 on the basis of the number of variant alleles. $P_{\text {interaction }}$ was for the differences in ORs between African-American and European-American women, and a $P_{\text {interaction }}$ of less than 0.10 was deemed significant. ${ }^{a}$ Singlenucleotide polymorphism (SNP) rs2239186 in VDR remained significant after correction for multiple comparison by permutation. 
Table 3 Single-nucleotide polymorphisms in VDR and CYP24A1 and differential association with estrogen receptorspecific breast cancer risk among African-American and European-American women

\begin{tabular}{|c|c|c|c|c|c|c|c|c|c|}
\hline \multirow[b]{2}{*}{ Gene } & \multirow[b]{2}{*}{ SNP } & \multirow[b]{2}{*}{ Genotype } & \multicolumn{2}{|c|}{ African-American } & \multicolumn{4}{|c|}{ European-American } & \multirow[b]{2}{*}{$P_{\text {interaction }}$} \\
\hline & & & Cases/Controls & OR $(95 \% \mathrm{Cl})$ & $P_{\text {trend }}$ & Cases/Controls & OR $(95 \% \mathrm{Cl})$ & $P_{\text {trend }}$ & \\
\hline \multirow[t]{2}{*}{$V D R$} & rs10783218 & GG & $178 / 304$ & 1.00 & 0.82 & $194 / 352$ & 1.00 & 0.04 & 0.04 \\
\hline & & GA/AA & $85 / 150$ & $0.96(0.69-1.34)$ & & $20 / 17$ & $2.05(1.02-4.12)$ & & \\
\hline \multirow[t]{3}{*}{$V D R$} & rs3819545 & $\mathrm{AA}$ & $71 / 242$ & 1.00 & 0.04 & $22 / 162$ & 1.00 & 0.38 & 0.04 \\
\hline & & $A G$ & $45 / 168$ & $0.91(0.59-1.40)$ & & $26 / 156$ & $1.22(0.66-2.26)$ & & \\
\hline & & GG & $3 / 43$ & $0.23(0.07-0.77)$ & & $11 / 52$ & $1.40(0.62-3.15)$ & & \\
\hline \multirow[t]{3}{*}{ CYP24A1 } & rs927650 & GG & $66 / 258$ & 1.00 & 0.62 & $10 / 116$ & 1.00 & 0.003 & 0.10 \\
\hline & & GA & $47 / 170$ & $1.09(0.71-1.68)$ & & $29 / 186$ & $1.76(0.81-3.78)$ & & \\
\hline & & AA & $8 / 27$ & $1.18(0.50-2.79)$ & & $20 / 68$ & $3.46(1.50-7.96)$ & & \\
\hline \multirow[t]{3}{*}{ CYP24A1 } & rs1570669 & GG & $15 / 81$ & 1.00 & 0.69 & $32 / 158$ & 1.00 & 0.03 & 0.05 \\
\hline & & GA & $69 / 219$ & $1.77(0.94-3.31)$ & & $24 / 162$ & $0.71(0.40-1.27)$ & & \\
\hline & & AA & $37 / 154$ & $1.36(0.69-2.67)$ & & $3 / 50$ & $0.28(0.08-0.97)$ & & \\
\hline \multirow[t]{2}{*}{ CYP24A1 } & rs2209314 & $\mathrm{AA}$ & 102/393 & 1.00 & 0.33 & $46 / 208$ & 1.00 & 0.004 & 0.003 \\
\hline & & $A G / G G$ & 19/61 & $1.34(0.74-2.40)$ & & $13 / 162$ & $0.38(0.20-0.73)$ & & \\
\hline \multirow[t]{3}{*}{ CYP24A1 } & rs3787555 & CC & $79 / 326$ & 1.00 & 0.02 & $25 / 175$ & 1.00 & 0.91 & 0.09 \\
\hline & & $C A$ & $37 / 122$ & $1.42(0.90-2.24)$ & & $29 / 155$ & $1.25(0.69-2.24)$ & & \\
\hline & & AA & $5 / 7$ & 3.79 (1.11-12.91) & & $5 / 38$ & $0.83(0.30-2.35)$ & & \\
\hline \multirow[t]{3}{*}{ CYP24A1 } & rs2762941 & AA & $16 / 120$ & 1.00 & 0.004 & $24 / 132$ & 1.00 & 0.54 & 0.05 \\
\hline & & $A G$ & $61 / 212$ & $1.97(1.07-3.61)$ & & $26 / 168$ & $0.89(0.49-1.65)$ & & \\
\hline & & GG & $44 / 122$ & $2.62(1.38-4.98)$ & & $9 / 68$ & $0.78(0.34-1.78)$ & & \\
\hline \multirow[t]{3}{*}{ CYP24A1 } & rs4809959 & GG & $32 / 133$ & 1.00 & 0.99 & $14 / 131$ & 1.00 & 0.01 & 0.07 \\
\hline & & GA & $64 / 223$ & $1.13(0.70-1.83)$ & & $26 / 172$ & $1.43(0.71-2.88)$ & & \\
\hline & & AA & $25 / 98$ & $0.98(0.54-1.78)$ & & 19/66 & $2.71(1.25-5.86)$ & & \\
\hline \multirow[t]{3}{*}{ CYP24A1 } & rs2585428 & GG & $27 / 109$ & 1.00 & 0.65 & $26 / 90$ & 1.00 & 0.006 & 0.02 \\
\hline & & GA & $66 / 246$ & $1.12(0.67-1.87)$ & & $22 / 175$ & $0.46(0.24-0.87)$ & & \\
\hline & & AA & $28 / 100$ & $1.15(0.63-2.10)$ & & $11 / 105$ & $0.36(0.17-0.79)$ & & \\
\hline
\end{tabular}

Odds ratio (OR) and 95\% confidence interval $(\mathrm{Cl})$ are adjusted for covariates, including age, proportion of European ancestry, body mass index, family history of breast cancer, and education. $P_{\text {trend }}$ was for genetic dose response by coding genotypes as 0,1 , and 2 on the basis of the number of variant alleles. $P_{\text {interaction }}$ was for the differences in ORs between African-American and European-American women, and a $P_{\text {interaction }}$ of less than 0.10 was deemed significant. SNP, singlenucleotide polymorphism.

on cultured lymphoblastoid cells [32], were also lower in AA women. In a previous study among EA women, we found that low 25OHD levels were associated with increased risk of $\mathrm{ER}^{-}$breast cancer, both in comparison with controls and with women with $\mathrm{ER}^{+}$breast cancer [22]. Given all of these data, it is possible that low $25 \mathrm{OHD}$ levels in AA women, coupled with unique 'at- risk' genetic variants, contribute, in part, to the higher prevalence of $\mathrm{ER}^{-}$breast cancer among AA women. If these potential associations were to be consistently observed in future studies, our results would support a public health effort for vitamin D supplementation to reduce risk of aggressive breast cancer among AA women.

Table 4 Changes in risk of estrogen receptor-negative breast cancer by race with inclusion of single-nucleotide polymorphisms in CYP24A1

\begin{tabular}{lccc}
\hline Model & Variable & Adjusted OR (95\% CI) & Palue \\
\hline Base model & Race (AA versus EA) & $1.53(1.06-2.22)$ & 0.02 \\
\hline Base model + SNPs & Race (AA versus EA) & $1.20(0.80-1.79)$ & 0.38 \\
\hline & rs2209314 (AG/GG versus AA) & $0.57(0.36-0.89)$ & 0.01 \\
\hline rs2762941 (AG versus AA) & $1.47(0.96-2.25)$ & 0.04 \\
\hline
\end{tabular}

Covariates included in the base model were age at diagnosis, body mass index, family history of breast cancer, education, and race. Odds ratio (OR) and $95 \%$ confidence interval $(\mathrm{Cl})$ for race after adjustment for other covariates are shown. Based on this model, seven single-nucleotide polymorphisms (SNPs) in CYP24A1 (rs927650, rs1570669, rs2209314, rs3787555, rs2762941, rs4809959, and rs2585428) and one SNP in VDR (rs3819545) that were associated with estrogen receptornegative (ER) breast cancer risk in either African-American (AA) or European-American (EA) women were entered and backward-selected. Two SNPs, rs2209314 and rs2762941, remained in the final model with a $P$ value of less than 0.05 . ORs and $95 \% \mathrm{Cls}$ for race and the two SNPs are shown. 
The finding of an inverse association between African ancestry estimated by AIMs and blood 25OHD levels is consistent with a recent community cohort study of AA men and women [33]. Our findings of extensive racial differences in allele frequencies and LD patterns for SNPs in $V D R$ and $C Y P 24 A 1$ are also consistent with those from an earlier study [12]. Previous studies on $V D R$ polymorphisms and breast cancer risk have focused on only a few SNPs. However, we did not find any relationship with Fok1, Bsm1, or Taq1 or a three-SNP haplotype consisting of Bsm1, Apa1, and Taq1 in either AA or EA women. The variant homozygote of Apa1 was associated with increased risk of breast cancer in EA women, but the effect was limited to post-menopausal women. Increased risk of breast cancer was also reported in a previous study for Apa1 [34]; however, results in the literature are conflicting $[35,36]$. The $\mathrm{G}$ allele of $\mathrm{Cdx} 2$ was associated with lower risk of breast cancer in AA women in our study and this finding was in contrast to the speculated functional alteration that the variant $G$ allele resulted in lower binding of the $\mathrm{Cdx} 2$ protein and thus lower transcriptional activity of VDR $[37,38]$. Similar to a study among women in Germany [39], our study found no association of $\mathrm{Cdx} 2$ with breast cancer risk in EA women.

To date, three studies have examined selected SNPs in $V D R$ with breast cancer risk in both AA and EA women. Two of them did not find associations for Fok1, Bsm1, Bgl1 (rs739837), or the 3' untranslated region poly(A) microsatellite in either AA or EA women [40,41], and a third study found increased risk by Bsm1 variant in EA but not AA women [42]. However, none of the above studies examined the associations by ER status or used the systematic approach we employed to capture variation across the genes.

We found that four SNPs in $V D R$ and two SNPs in $C Y P 24 A 1$ had differential associations with breast cancer by race ( $P$ for interaction was not more than 0.10$)$. The fact that the associations were not consistent in AA and EA populations corroborates the differences in blood levels of vitamin D and frequency and LD pattern of vitamin D-related genetic variants, implying that the racespecific associations might be the result of gene-environment interactions. In further analyses stratified by ER status, one SNP in VDR and seven SNPs in CYP24A1 were specifically associated with $\mathrm{ER}^{-}$but not $\mathrm{ER}^{+}$cancer risk, and the associations differed between AA and EA women. Controlling for the two SNPs in CYP24A1 in a multivariate model substantially reduced the increased $E R^{-}$ breast cancer risk associated with AA race and made the association no longer significant. This provides the first evidence supporting the contribution of vitamin D-related genetic variants to higher risk of more aggressive breast cancer in AA women.
We found significant associations between breast cancer risk and a number of tag SNPs in $V D R$ without previously known functionality. However, in our analyses, SNP rs2239186 was associated with increased serum levels of $25 \mathrm{OHD}$ in AA women without breast cancer. This SNP and a haplotype containing it were also significantly associated with reduced breast cancer risk in AA women, irrespectively of ER status. This SNP resides in an intronic region and thus is unlikely to be the causal variant. However, it may be a marker for a causal SNP outside of the $V D R$ gene. This SNP has not been implicated in other breast cancer studies but has been shown to be associated with reduced risk of colorectal cancer in individuals with low vitamin D intake [43] and was also implicated in type I diabetes [44]. This SNP may warrant future replication and fine-mapping studies.

The two SNPs, rs2209314 and rs2762941, in CYP24A1 shown to be associated with racial differences in $\mathrm{ER}^{-}$breast cancer risk are intronic. Although these SNPs have not been implicated previously in breast cancer, elevated expression of CYP24A1 was found in breast cancer tissues [45], indicating a potential role in breast cancer etiology. We did not observe associations of these two SNPs in CYP24A1 with serum 25OHD levels in either AA or EA populations, indicating that these two SNPs themselves or linked causal variants may affect ER- breast cancer not through altering circulating 25OHD levels but availability of vitamin $\mathrm{D}$ in local mammary tissues.

One limitation of our study is the lack of validation for the significant findings. The number of patients with breast cancer and controls was relatively limited, especially after stratification by race and ER status. None of the associations with SNPs, except for rs2239186, remained significant after correction for multiple comparisons. We thus could not exclude the possibility of false-positive findings in our data. However, the fact that rs2239186 was associated with higher serum 250HD levels in AA women as well as reduced breast cancer risk in this population is biologically coherent and reduces the likelihood of spurious findings for this VDR SNP. Another limitation is that only three genes in vitamin D-related pathways were included in this study. Although VDR, CYP27B1, and CYP24A1 are the three key genes in this pathway, genes encoding for some other vitamin D metabolizing enzymes, particularly $G C$ encoding for vitamin D binding protein (which has been related to circulating vitamin $\mathrm{D}$ levels), may also be related to breast cancer risk and warrant further studies. AA women are more likely to develop breast cancer at a younger age than EAs; we enrolled all eligible AA women but randomly selected eligible EA women, frequencymatching by 5 -year age categories. We also initially limited eligibility to women 65 years or younger because of low participation of older women without breast cancer to case-control studies. Thus, the overall study population is 
younger than that of some other studies. Although we found no evidence of modification effects by menopausal status for any but two SNPs (Table S5 of Additional file 1 ), the high proportion of pre-menopausal women in this study needs to be considered in relation to generalizability.

\section{Conclusions}

We found notable differences in blood levels of 25OHD and genetic variants in $V D R$ and CYP24A1 between AA and EA women. Specifically, we found race-specific associations with breast cancer risk and these associations may be due to distinct genetic background and differences in 25OHD levels between the two populations. Our study provides evidence that variants in vitamin Drelated genes may contribute to higher risk of $\mathrm{ER}^{-}$breast cancer in AA than EA women. Future studies are warranted to validate our findings and to investigate whether pre-diagnostic blood levels of 25OHD may also be related to racial differences in risk of $\mathrm{ER}^{-}$breast cancer.

\section{Additional material}

Additional file 1: Supplementary Tables S1-S5. The file contains the following five supplementary tables. Table S1. Breast cancer risk associated with SNPs in VDR, CYP27B1, and CYP24A1 in African American and European American women. Table S2. Haplotypes of VDR and CYP24A1 in significant association with breast cancer risk in African American and European American women. Table S3. Risk of estrogen receptor positive breast cancer associated with SNPs in VDR, CYP27B1, and CYP24A1 in African Americana and European American women. Table S4. Risk of estrogen receptor negative breast cancer associated with SNPs in VDR, CYP27B1, and CYP24A1 in African Americana and European American women. Table S5. SNPs in VDR that show differential associations with breast cancer stratified by menopausal status in African American and European American women.

\section{Abbreviations \\ 25OHD: 25-hydroxyvitamin D; AA: African-American; AlM: ancestry informative marker; BMI: body mass index; CEU: Utah residents with ancestry from Northern and Western Europe; Cl: confidence interval; EA: European- American; ER: estrogen receptor; LCL: lymphoblastoid cell line; LD: linkage disequilibrium; OR: odds ratio; PR: progesterone receptor; SNP: single- nucleotide polymorphism; UV: ultraviolet; VDR: vitamin D receptor; WCHS: Women's Circle of Health Study; YRI: Yoruba in Ibadan.}

\section{Acknowledgements}

This work was supported by grants from the US Army Medical Research and Material Command (DAMD-17-01-1-0334), the National Cancer Institute (R01 CA100598 and P01 CA151135), and the Breast Cancer Research Foundation and a gift from the Philip L Hubbell family. SY was the recipient of a predoctoral training award from the Department of Defense Breast Cancer Research Program (W81XWH-08-1-0223). EVB was the recipient of a career transition award from the National Cancer Institute (K22 CA138563). Samples were stored and managed by the Roswell Park Cancer Institute (RPCI) DataBank and BioRepository, and genotyping was performed in the RPCl Genomics Core Facility; both are Cancer Center Support Grant-shared resources supported by P30 CA016056-32. The New Jersey State Cancer Registry (NJSCR) is a participant in the Centers for Disease Control and Prevention's National Program of Cancer Registries and is a National Cancer Institute Surveillance, Epidemiology, and End Results (SEER) Expansion
Registry. The NJSCR is supported by the Centers for Disease Control and Prevention under cooperative agreement DP07-703 awarded to the New Jersey Department of Health \& Senior Services. The collection of State of New Jersey cancer incidence data is also supported by the National Cancer Institute's SEER Program under contract N01-PC-95001-20. The funding agents played no role in design, in the collection, analysis, and interpretation of data, in the writing of the manuscript, or in the decision to submit the manuscript for publication.

We are grateful to the women who participated in this study and to colleagues, physicians, and clinical staff at participating hospitals in New York who facilitated identification and enrollment of cases into the study: Kandace Amend (i3 Drug Safety), Helena Furberg (Memorial Sloan-Kettering Cancer Center), Thomas Rohan and Joseph Sparano (Albert Einstein College of Medicine), Kitwaw Demissie (University of Medicine and Dentistry of New Jersey), Paul Tartter and Alison Estabrook (St. Luke's Roosevelt Hospital), James Reilly (Kings County Hospital Center), Benjamin Pace, George Raptis, and Christina Weltz (Mount Sinai School of Medicine), Maria Castaldi (Jacob Medical Center), Sheldon Feldman (New York-Presbyterian), and Margaret Kemeny (Queens Hospital Center). We also thank Dr. Eileen M. Dolan for the permission for using the expression data of vitamin D receptor in HapMap lymphoblastoid cell lines.

\section{Author details}

'Department of Cancer Prevention \& Control, Roswell Park Cancer Institute, Elm and Carlton Streets, Buffalo, NY 14263, USA. ${ }^{2}$ University of Pittsburgh Cancer Institute, University of Pittsburgh, 5150 Centre Avenue, Pittsburgh, PA 15232, USA. ${ }^{3}$ Department of Oncological Sciences, Mount Sinai School of Medicine, One Gustave L. Levy Place, New York, NY 10029, USA. ${ }^{4}$ Department of Pathology, Roswell Park Cancer Institute, Elm and Carlton Streets, Buffalo, NY 14263, USA. ${ }^{5}$ Department of Pharmacology and Therapeutics, Roswell Park Cancer Institute, Elm and Carlton Streets, Buffalo, NY 14263, USA. ${ }^{6}$ Department of Medicine, Roswell Park Cancer Institute, Elm and Carlton Streets, Buffalo, NY 14263, USA. ${ }^{7}$ New Jersey State Cancer Registry, New Jersey Department of Health \& Senior Services, 369 South Warren Street, Trenton, NJ 08608, USA. ${ }^{8}$ The Cancer Institute of New Jersey, Robert Wood Johnson Medical School, 125 Paterson Street, New Brunswick, NJ 08901, USA.

\section{Authors' contributions}

SY helped to develop the hypothesis, design the study, and perform the data analysis and interpretation. CBA helped to develop the hypothesis, design the study, provide the data and biospecimen from the WCHS, perform the data analysis and interpretation, and provide financial support for the study. GZ helped to provide the data and biospecimen from the WCHS and to perform the data analysis and interpretation. DHB, $\sqcup, M R, G C$, WD, KSP, and EVB helped to provide the data and biospecimen from the WCHS. HH provided pathological data of tumor samples. C-CH, LES, LT, CSJ, $D L T, S E M$ and FA helped to perform the data analysis and interpretation. HZ helped to provide financial support for the study. All authors read and approved the final draft of the manuscript.

\section{Competing interests}

The authors declare that they have no competing interests.

Received: 15 November 2011 Revised: 7 February 2012 Accepted: 4 April 2012 Published: 4 April 2012

\section{References}

1. Amend K, Hicks D, Ambrosone CB: Breast cancer in African-American women: differences in tumor biology from European-American women. Cancer Res 2006, 66:8327-8330.

2. Ooi LL, Zhou H, Kalak R, Zheng Y, Conigrave AD, Seibel MJ, Dunstan CR: Vitamin $D$ deficiency promotes human breast cancer growth in a murine model of bone metastasis. Cancer Res 2010, 70:1835-1844.

3. Fumagalli M, Sironi M, Pozzoli U, Ferrer-Admettla A, Pattini L, Nielsen R: Signatures of environmental genetic adaptation pinpoint pathogens as the main selective pressure through human evolution. PLOS Genet 2011, 7:e100235.

4. Yuen AW, Jablonski NG: Vitamin D: in the evolution of human skin colour. Med Hypotheses 2010, 74:39-44. 
5. Jablonski NG: The evolution of human skin and skin color. Ann Rev Anthropol 2004, 33:585-623.

6. Chaplin G, Jablonski NG: Vitamin D and the evolution of human depigmentation. Am J Phys Anthropol 2009, 139:451-461.

7. Clemens TL, Adams JS, Henderson SL, Holick MF: Increased skin pigment reduces the capacity of skin to synthesise vitamin D3. Lancet 1982, 1:74-76.

8. Nesby-O'Dell S, Scanlon KS, Cogswell ME, Gillespie C, Hollis BW, Looker AC, Allen C, Doughertly C, Gunter EW, Bowman BA: Hypovitaminosis D prevalence and determinants among African American and white women of reproductive age: third National Health and Nutrition Examination Survey, 1988-1994. Am J Clin Nutr 2002, 76:187-192.

9. Ginde AA, Liu MC, Camargo CA Jr: Demographic differences and trends of vitamin D insufficiency in the US population, 1988-2004. Arch Intern Med 2009, 169:626-632.

10. Wejse C, Olesen R, Rabna P, Kaestel P, Gustafson P, Aaby P, Andersen PL, Glerup H, Sodemann M: Serum 25-hydroxyvitamin D in a West African population of tuberculosis patients and unmatched healthy controls. Am J Clin Nutr 2007, 86:1376-1383.

11. Deeb KK, Trump DL, Johnson CS: Vitamin D signalling pathways in cancer: potential for anticancer therapeutics. Nat Rev Cancer 2007, 7:684-700.

12. Nejentsev S, Godfrey L, Snook H, Rance H, Nutland S, Walker NM, Lam AC, Guja C, Ionescu-Tirgoviste C, Undlien DE, Ronningen KS, Tuomilehto-Wolf E, Tuomilehto J, Newport MJ, Clayton DG, Todd JA: Comparative highresolution analysis of linkage disequilibrium and tag single nucleotide polymorphisms between populations in the vitamin D receptor gene. Hum Mol Genet 2004, 13:1633-1639.

13. Zinser $\mathrm{G}$, Packman $\mathrm{K}$, Welsh J: Vitamin $\mathrm{D}(3)$ receptor ablation alters mammary gland morphogenesis. Development 2002, 129:3067-3076.

14. Welsh J: Vitamin $D$ and breast cancer: insights from animal models. Am J Clin Nutr 2004, 80:1721S-1724S.

15. Welsh J: Vitamin D and prevention of breast cancer. Acta Pharmacol Sin 2007, 28:1373-1382.

16. International Agency for Research on Cancer: Vitamin D and cancer. In IACR Working Group Reports. Volume 5. Lyon, France: International Agency for Research on Cancer; 2008.

17. Chlebowski RT, Johnson KC, Kooperberg C, Pettinger M, WactawskiWende J, Rohan T, Rossouw J, Lane D, O'Sullivan MJ, Yasmeen S, Hiatt RA, Shikany JM, Vitolins M, Khandekar J, Hubbell FA: Calcium plus vitamin D supplementation and the risk of breast cancer. J Natl Cancer Inst 2008, 100:1581-1591.

18. Zinser GM, Suckow M, Welsh J: Vitamin D receptor (VDR) ablation alters carcinogen-induced tumorigenesis in mammary gland, epidermis and lymphoid tissues. J Steroid Biochem Mol Biol 2005, 97:153-164.

19. Neuhouser ML, Sorensen B, Hollis BW, Ambs A, Ulrich CM, McTiernan A, Bernstein L, Wayne S, Gilliland F, Baumgartner K, Baumgartner R, BallardBarbash R: Vitamin $D$ insufficiency in a multiethnic cohort of breast cancer survivors. Am J Clin Nutr 2008, 88:133-139.

20. Abbas S, Chang-Claude J, Linseisen J: Plasma 25-hydroxyvitamin D and premenopausal breast cancer risk in a German case-control study. Int J Cancer 2009, 124:250-255.

21. Abbas S, Linseisen J, Chang-Claude J: Dietary vitamin D and calcium intake and premenopausal breast cancer risk in a German case-control study. Nutr Cancer 2007, 59:54-61.

22. Yao S, Sucheston LE, Millen AE, Johnson CS, Trump DL, Nesline MK, Davis W, Hong CC, McCann SE, Hwang H, Kulkarni S, Edge SB, O'Connor TL, Ambrosone CB: Pretreatment serum concentrations of 25-hydroxyvitamin $\mathrm{D}$ and breast cancer prognostic characteristics: a case-control and a case-series study. PLoS One 2011, 6:e17251.

23. Ambrosone CB, Ciupak GL, Bandera EV, Jandorf L, Bovbjerg DH, Zirpoli G, Pawlish K, Godbold J, Furberg H, Fatone A, Valdimarsdottir H, Yao S, Li Y, Hwang H, Davis W, Roberts M, Sucheston L, Demissie K, Amend KL, Tartter P, Reilly J, Pace BW, Rohan T, Sparano J, Raptis G, Castaldi M, Estabrook A, Feldman S, Weltz C, Kemeny M: Conducting molecular epidemiological research in the age of HIPAA: a multi-institutional casecontrol study of breast cancer in African-American and EuropeanAmerican women. J Oncol 2009, 2009:871250.

24. The International HapMap Consortium: The International HapMap Project. Nature 2003, 426:789-796.

25. SeattleSNPs Genome Variation Server. [http://gvs.gs.washington.edu/GVS/]
26. Xu Z, Kaplan NL, Taylor JA: TAGster: efficient selection of LD tag SNPs in single or multiple populations. Bioinformatics 2007, 23:3254-3255.

27. Tsai HJ, Choudhry S, Naqvi M, Rodriguez-Cintron W, Burchard EG, Ziv E: Comparison of three methods to estimate genetic ancestry and control for stratification in genetic association studies among admixed populations. Hum Genet 2005, 118:424-433.

28. Pritchard JK, Stephens M, Donnelly P: Inference of population structure using multilocus genotype data. Genetics 2000, 155:945-959.

29. Luna A, Nicodemus KK: snp.plotter: an R-based SNP/haplotype association and linkage disequilibrium plotting package. Bioinformatics 2007, 23:774-776.

30. Gabriel SB, Schaffner SF, Nguyen H, Moore JM, Roy J, Blumenstiel B, Higgins J, DeFelice M, Lochner A, Faggart M, Liu-Cordero SN, Rotimi C, Adeyemo A, Cooper R, Ward R, Lander ES, Daly MJ, Altshuler D: The structure of haplotype blocks in the human genome. Science 2002, 296:2225-2229.

31. Purcell S, Neale B, Todd-Brown K, Thomas L, Ferreira MA, Bender D, Maller J, Sklar P, de Bakker PI, Daly MJ, Sham PC: PLINK: a tool set for wholegenome association and population-based linkage analyses. Am J Hum Genet 2007, 81:559-575.

32. Zhang W, Duan S, Kistner EO, Bleibel WK, Huang RS, Clark TA, Chen TX, Schweitzer AC, Blume JE, Cox NJ, Dolan ME: Evaluation of genetic variation contributing to differences in gene expression between populations. Am J Hum Genet 2008, 82:631-640.

33. Signorello LB, Williams SM, Zheng W, Smith JR, Long J, Cai $Q$ Hargreaves MK, Hollis BW, Blot WJ: Blood vitamin d levels in relation to genetic estimation of African ancestry. Cancer Epidemiol Biomarkers Prev 2010, 19:2325-2331.

34. Curran JE, Vaughan T, Lea RA, Weinstein SR, Morrison NA, Griffiths LR: Association of A vitamin D receptor polymorphism with sporadic breast cancer development. Int J Cancer 1999, 83:723-726.

35. Sillanpaa P, Hirvonen A, Kataja V, Eskelinen M, Kosma VM, Uusitupa M, Vainio $H$, Mitrunen $K$ : Vitamin $D$ receptor gene polymorphism as an important modifier of positive family history related breast cancer risk. Pharmacogenetics 2004, 14:239-245.

36. Hou MF, Tien YC, Lin GT, Chen CJ, Liu CS, Lin SY, Huang TJ: Association of vitamin $D$ receptor gene polymorphism with sporadic breast cancer in Taiwanese patients. Breast Cancer Res Treat 2002, 74:1-7.

37. Arai H, Miyamoto Kl, Yoshida M, Yamamoto H, Taketani Y, Morita K, Kubota M, Yoshida S, Ikeda M, Watabe F, Kanemasa Y, Takeda E: The polymorphism in the caudal-related homeodomain protein $\mathrm{Cdx}-2$ binding element in the human vitamin $D$ receptor gene. J Bone Miner Res 2001, 16:1256-1264.

38. Fang $Y$, van Meurs JB, Bergink AP, Hofman A, van Duijn CM, van Leeuwen JP, Pols HA, Uitterlinden AG: Cdx-2 polymorphism in the promoter region of the human vitamin $D$ receptor gene determines susceptibility to fracture in the elderly. J Bone Miner Res 2003, 18:1632-1641.

39. Abbas S, Nieters A, Linseisen J, Slanger T, Kropp S, Mutschelknauss EJ, Flesch-Janys D, Chang-Claude J: Vitamin D receptor gene polymorphisms and haplotypes and postmenopausal breast cancer risk. Breast Cancer Res 2008, 10:R31.

40. John EM, Schwartz GG, Koo J, Wang W, Ingles SA: Sun exposure, vitamin D receptor gene polymorphisms, and breast cancer risk in a multiethnic population. Am J Epidemiol 2007, 166:1409-1419.

41. VandeVord PJ, Wooley PH, Darga LL, Severson RK, Wu B, Nelson DA: Genetic determinants of bone mass do not relate with breast cancer risk in US white and African-American women. Breast Cancer Res Treat 2006, 100:103-107.

42. Trabert B, Malone KE, Daling JR, Doody DR, Bernstein L, Ursin G, Marchbanks PA, Strom BL, Humphrey MC, Ostrander EA: Vitamin D receptor polymorphisms and breast cancer risk in a large populationbased case-control study of Caucasian and African-American women. Breast Cancer Res 2007, 9:R84.

43. Poynter JN, Jacobs ET, Figueiredo JC, Lee WH, Conti DV, Campbell PT, Levine AJ, Limburg P, Le Marchand L, Cotterchio M, Newcomb PA, Potter JD, Jenkins MA, Hopper JL, Duggan DJ, Baron JA, Haile RW: Genetic variation in the vitamin $\mathrm{D}$ receptor (VDR) and the vitamin D-binding protein $(\mathrm{GC})$ and risk for colorectal cancer: results from the Colon Cancer Family Registry. Cancer Epidemiol Biomarkers Prev 2010, 19:525-536. 
44. Kahles H, Morahan G, Todd JA, Badenhoop K: Association analyses of the vitamin D receptor gene in 1654 families with type I diabetes. Genes Immun 2009, 10(Suppl 1):S60-63.

45. Townsend K, Banwell CM, Guy M, Colston KW, Mansi JL, Stewart PM, Campbell MJ, Hewison M: Autocrine metabolism of vitamin D in normal and malignant breast tissue. Clin Cancer Res 2005, 11:3579-3586.

doi:10.1186/bcr3162

Cite this article as: Yao et al:: Variants in the vitamin D pathway, serum levels of vitamin $D$, and estrogen receptor negative breast cancer among African-American women: a case-control study. Breast Cancer Research 2012 14:R58.

Submit your next manuscript to BioMed Central and take full advantage of:

- Convenient online submission

- Thorough peer review

- No space constraints or color figure charges

- Immediate publication on acceptance

- Inclusion in PubMed, CAS, Scopus and Google Scholar

- Research which is freely available for redistribution

Submit your manuscript at www.biomedcentral.com/submit
() Biomed Central 